\title{
Unusual Intraluminal Processes of Capillaries in a Case of Undifferentiated Lung Cancer
}

\author{
Eng Seng Ang, Toshimiko Neyazaki, Chigashr Suzuki, \\ Fumio ARIJi* and JunJi Yamaguchi* \\ Department of Surgery and Department of Internal Medicine,* \\ The Research Institute for Tuberculosis, Leprosy and Cancer, \\ Tohoku University, Sendai
}

\begin{abstract}
Ang, E.S., Neyazaki, T., Suzuki, C., ARij, F. and Yamaguchi, J. Unusual Intraluminal Processes of Capillaries in a Case of Undifferentiated Lung Cancer. Tohoku J. exp. Med., 1973, 110 (1), 1-5__ Extremely long villous processes projected from endothelium toward capillary canal was observed in the blood vessels of very malignant pulmonary carcinoma. Many of the villous processes appeared to be long enough to interconnect and to interwind each other, and some of them showed waving or rolling shape. There are numerous vesicles in various sizes within the capillary endothelium from which these processes are projected. A correlation between the rapid growth of lung cancer and these unusual findings is not known at present. ——_- electronmicroscopy; malignant carcinoma vessel; villous processe
\end{abstract}

The histopathology of pulmonary malignancies has been chiefly directed toward morphological classification of cancer cells. While we have been studying on the vasculature of human lung tumors, we encountered extraordinary intraluminal processes in tumor capillaries which were thought to be a rare evidence under electron microscope. To our knowledge, extremely long villus-like precesses have never been reported in the literature.

\section{REPORT of CASE}

A 52-year-old male was incidentally found to have an abnormal shadow on the right chest field and referred to our clinic in August, 1970. Right middle and lower lobectomies were performed under a diagnosis of lung cancer. Histopathological study confirmed the diagnosis of small cell carcinoma. Eight months later the patient was re-admitted with dyspnea and lumbago; X-ray examination revealed a recurrence of tumor on the right upper lobe of lung with a metastasis to the 6th thoracic vertebra. The patient died two weeks after the re-admission. After the lung cancer was detected, he lived only for ten months. This suggests that the tumor was of very malignant nature.

\section{Meterials and Methods}

The tissue samples were obtained from the area of $1 \mathrm{~cm}$ beneath the surface of the lung cancer which was removed by lobectomy, and fixed for 1 hour in $5 \%$ glutaraldehyde

Received for publication, June 29, 1972. 


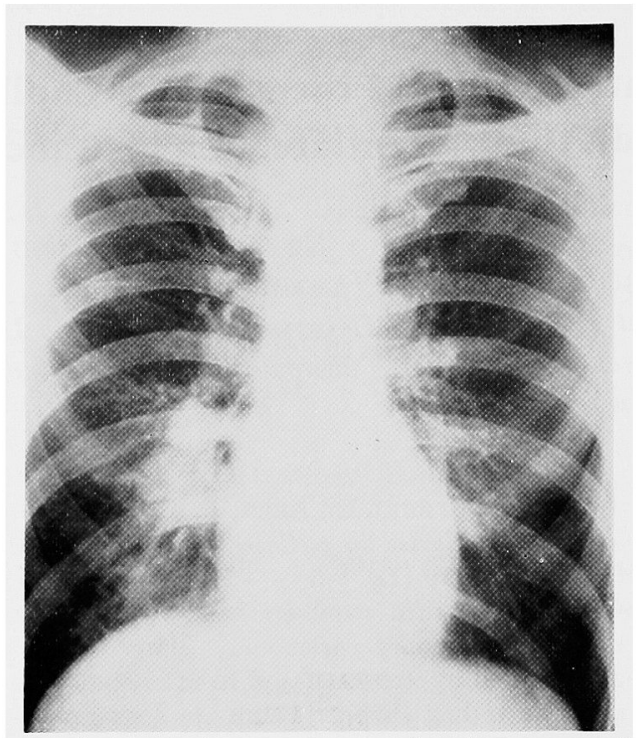

Fig. 1. Roentgenogram of chest prior to surgery showing a consolidation of the medial segment of middle lobe and lower lobe.

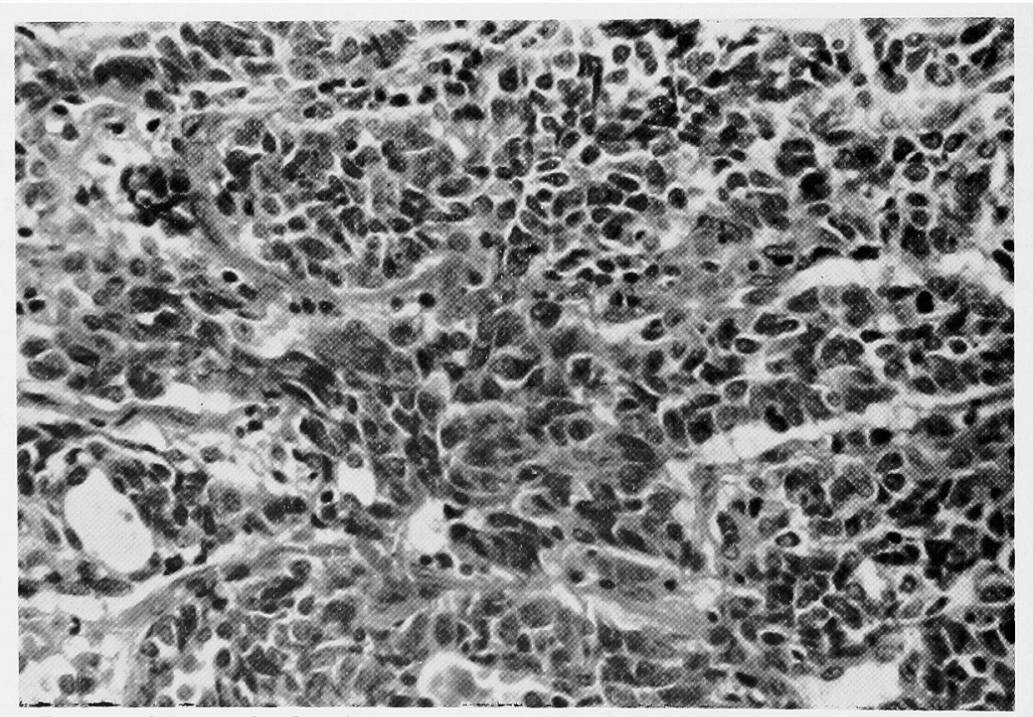

Fig. 2. Photo-micrograph showing a section of histoputhology of the undifferentiated lung cancer.

in Millonig's buffer at $\mathrm{pH}$ 7.3, followed then by fixation for 2 hours in $1 \%$ osmium tetroxide in Millonig's buffer at the same $\mathrm{pH}$. After fixation, tissues were dehydrated in an ethanol series and embedded in Epon 812. Sections for light microscopy and thin sections for electronmicroseopy were cut with glass knives on a Porter-Blum MT-2 microtome. The thin sections were double stained with saturated aqueous uranyl acetate followed by lead acetate and examined with a Hitachi $\mathrm{HU}-1 \mathrm{lB}$ electron microscope. 


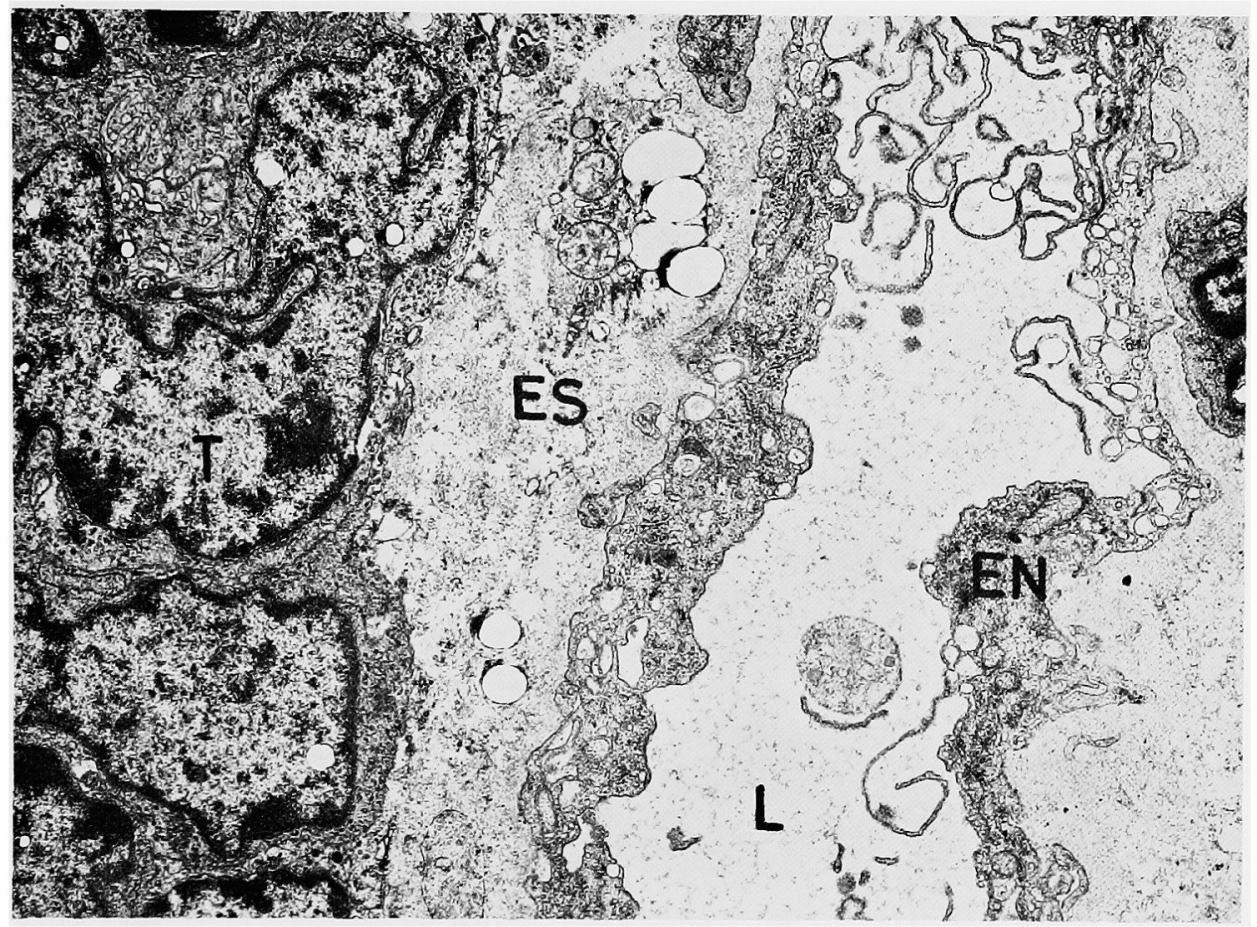

Fig. 3. Extremely long villous processes and prominant increase in vesicular formation on the intraluminal surface of endothelial cell. $(\times 8000)$

ES: Extracellar space

$\mathrm{T}$ : Tumor cell

\section{Results and Discussion}

Ultrastructural findings of capillaries in pulmonary undifferenciated carcinoma, shown in Figs. 2 and 3, were rather different from those of common conceptive types of capillaries in normal organs. The endothelial cells of vessels in tumor showed very irregular appearance in structure and extreme attenuation, and endothelial pseudopodia projected outward the surrounding space of the capillary were seen in several areas. Many clear vesicles in various sizes which might be formed by vigorous pinocytotic activity were present.

The most striking abnormality was to possess a great number of tremendously long villous processes arising from the intraluminal surface of endothelial cells. Many of the villous processes appeared to be long enough to interconnect and to interwind each other, and some appeared to make themselves in waving or rolling shapes.

This finding was coincident with a prominent increase of vesicles in number within the capillary endothelium. The basement membrane as well as pericytes was absent. The protrusion described as pseudopodia projecting into the lumen is thought to play a certain role in pinocytotic activity. The similar findings had been reported for other organs: heart, coronary artery, rat cerebral cortex, 


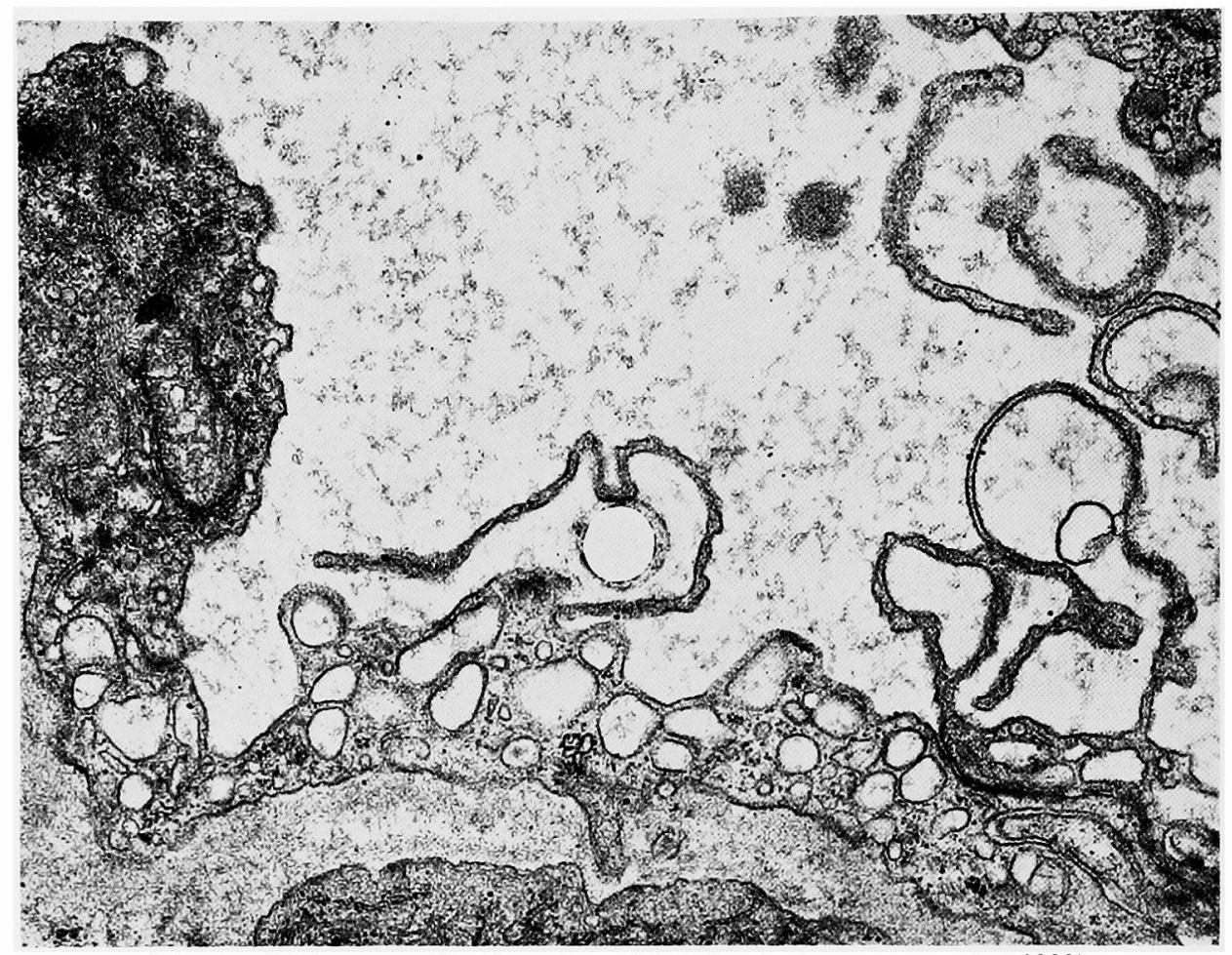

Fig. 4. Higher magnification view of intraluminal processes. $(\times 16000)$

parathyroid of Macaca multatta, mouse thymus, rabbit omentum and human placenta. The common appearance of these protrusions is simplely fingershaped, as described by Majno (1965) and no one has mentioned of the length of protrusions. Abe (1972), in a study on the thymus of patients with myasthenia gravis, found several different appearances of processes of $1 \mu$ in length. Long (1970), in a description of several types of human brain tumors, reported the same findings on intraluminal processes, which were described as "relatively long", but the length was not given.

The processes noticed in this study, should probably be visualized as long strings in a cross section. The longest process appeared to be $6 \mu$ in length. These processes were seen in various appearances, aud therefore it is likely that they play various activities such as transporting fluid or carrying substances of large molecules. The moderatelydense materials could be seen within the vesicles.

The correlation between the rapid growth of this lung cancer and the unusual electronmicroscopic findings is not clear at the present time. More extensive investigation should be required. 


\section{References}

1) Abe, Y. (1972) Unusual intraluminal processes of capillaries in a case of undifferentiated lung cancer. Igaku no Ayumi (Jap.), 81, 528-531.

2) Long, D.M. (1970) Capillary ultrastructure and the blood-brain barrier in human malignant brain tumors. $J$. Neurosurg., 32, 127-144.

3) Majno, G. (1965) Ultrastructure of the vascular membrane. In: Handbook of Physiology, edited by W.F. Hamilton, and Doweds P. American Physiological Society, Washington, Section 2, Vol. III, pp. 2293-2360. 